\title{
LA NEGACIÓN DE LA PARTE: LA CRISIS DE REPRESENTACIÓN POLÍTICA ARGENTINA
}

\author{
Nuria Yabkowski \\ Universidad Nacional de General Sarmiento, UBA-CONICET, Argentina \\ http://dx.doi.org/10.5209/rev_NOMA.2012.41784
}

\begin{abstract}
Resumen.- La crisis de representación política en Argentina -que ubicamos entre 1990 y 2002 , y tuvo su episodio más álgido en diciembre de 2001- ha tenido diversas interpretaciones desde las ciencias sociales, como es propio de todo fenómeno complejo y multidimensional. Aquí nos proponemos analizar algunas de ellas y, especialmente, aquella dimensión del fenómeno que se relaciona con los partidos políticos. Pues aun cuando aceptamos que la crisis fue de los partidos, todavía es necesario especificar cuál de sus dimensiones es la que se vio erosionada. De esta manera, y a diez años de ese 2001, podemos comenzar a comprender qué es lo que en lo que se ha transformado en estos últimos diez años para que, al mismo tiempo que los partidos continúan siendo cuestionados en su capacidad representativa, ya no sea posible describir la situación como una crisis de representación política. Concluimos así que los partidos "olvidaron" que una de sus más importantes funciones es la de contribuir a establecer a través de la palabra, los conflictos y los clivajes la diferencia propiamente política, a partir de la cual se conforma la comunidad política de la que forman parte.
\end{abstract}

Palabras clave.- crisis de representación política, partidos políticos, Argentina, diferencia, clivajes, identidad

\section{The denial of the part: the crisis of political representation in Argentina}

\begin{abstract}
The crisis of political representation in Argentina, which was developed between 1990 and 2002 and had its most intense episode in December 2001, has had various interpretations from the social sciences, as is characteristic of all complex and multidimensional phenomenon. Here we analyze some of them and especially the dimension of the phenomenon that is associated with political parties. Even if we accept that this was a crisis of political parties, it is still necessary to specify which of its dimensions is the one that was eroded. In this way, and ten years from 2001, can begin to understand what is changing in the last decade, while the parties continue to be challenged in his representative capacity, is no longer possible to describe the general situation as a crisis of political representation. We thus conclude that the parties "forgot" that one of its most important functions is to help establish through the word, the conflict and the political cleavages, the political difference, from which constitutes the political community.
\end{abstract}

Keywords.- crisis of political representation, political party, Argentina, difference, cleavages, identity

\footnotetext{
* Pertenencia institucional: UNGS-UBA-CONICET. Correo electrónico: nuriayaco@gmail.com. Doctoranda en Ciencias Sociales, Magíster en Investigación en Ciencias Sociales y Licenciada en Sociología (UBA). Becaria del CONICET (período 2007-2012). Docente de la UBA y del Instituto del Desarrollo Humano de la Universidad Nacional de General Sarmiento (en la Lic. en Estudios Políticos), donde desarrolla su investigación doctoral sobre la identidad kirchnerista. Cuenta con un libro publicado en coautoría con E. Dipaola (En tu ardor y en tu frío. Arte y política en Theodor Adorno y Gilles Deleuze, Paidós, 2008), varios capítulos en libros colectivos, artículos en revistas académicas y presentaciones a congresos nacionales e internacionales.
} 


\section{Introducción}

La crisis de representación política en Argentina -que se desarrolló entre 1990 y 2002, ${ }^{1}$ y tuvo su episodio más álgido en diciembre de 2001- ha tenido numerosas y diversas interpretaciones desde las ciencias sociales, como es propio de todo fenómeno complejo y multidimensional. En este trabajo nos proponemos analizar algunas de ellas y, especialmente, aquella dimensión del fenómeno que se relaciona con los partidos políticos. De este modo, y adoptando la forma de un debate, construimos una interpretación propia no sólo en lo que atañe al sentido de la crisis de representación, sino también en lo que respecta al rol de los partidos que, adelantamos, no se reduce a su papel institucional. Es decir, si aceptamos que la crisis fue de los partidos, todavía es necesario especificar cuál de sus dimensiones es la que se vio erosionada. De esta manera, y a diez años de ese 2001, podemos comenzar a comprender qué es lo que en lo que se ha transformado en estos últimos diez años para que, al mismo tiempo que los partidos continúan siendo cuestionados en su capacidad representativa, ya no sea posible describir la situación como una crisis de representación política.

Volver a pensar el sentido de esta crisis es, además, un ejercicio de interpretación sobre nuestro pasado más reciente, sobre el acontecimiento que deja una marca fundante en el proceso político que comenzó en 2003 y aún continúa. Por este motivo sigue siendo necesario disputar su sentido, especialmente si éste aparece como un debate ya saldado. Encaramos el trabajo revisando las interpretaciones académicas al respecto, pues este modo de aproximación nos permite discutir el efecto de sentido, pero también aquello que lo produce, es decir, los conceptos que sostienen cada uno de los análisis. En este sentido, teoría y análisis político se vuelven inseparables, por este motivo debemos exponer, aunque más no sea en una nota al pie, la perspectiva teórica desde la cual se realizan cada una de las lecturas.

\footnotetext{
${ }^{1}$ Esta periodización se justifica en el hito que constituyó la hiperinflación de 1989, ya que desde ese momento $-\mathrm{y}$ casi todos los analistas coinciden en esto- comenzaron a transformarse estructuralmente las relaciones de representación. Excluimos entonces el período de la llamada "transición democrática", ya que éste se encuentra atravesado por otras problemáticas. Por otra parte, consideramos que en el año 2003 comenzó un proceso de reconstitución del lazo representativo que todavía no ha concluido, y que constituye una de las transformaciones políticas-culturales más importantes de la última década.
} 


\section{Las teorías del desajuste}

Juan Carlos Torre entiende que esta crisis de representación no implica un fenómeno generalizado de desafección política, sino que, por el contrario, demuestra la vitalidad de las expectativas democráticas de la ciudadanía (Torre, 2003: 647). Y, más específicamente, sostiene que esta crisis debe explicarse por el comportamiento electoral del polo no peronista de la ciudadanía, puesto que, en realidad, esta crisis afectó especialmente a los partidos que pretendían representar a este sector, mientras que el peronismo mantiene la relación con su electorado, aunque durante los '90 y luego del 2001 atraviese una crisis de cohesión como máquina partidaria. Si Torre decide colocar su atención en esta parte del electorado es porque la dinámica de la competencia en la política electoral nacional entre 1983 y 1999 se explica, fundamentalmente, por el comportamiento del polo no peronista y dentro de él por las opciones electorales del centro-derecha y del centro-izquierda. Es allí donde está la fuente principal de la volatilidad del voto y también de los cambios en las coaliciones electorales. (...) Es allí donde está localizado, asimismo, el epicentro de la crisis de representación partidaria (Ibíd.: 652).

Torre concluye que la fidelidad del electorado peronista se mantuvo, mientras que fue el polo no peronista (votantes del FREPASO y de Acción por la República) el que contribuyó a forjar la interpretación de que los resultados de 2001 eran la muestra del descrédito general hacia el conjunto de los partidos políticos. Fue este sector el que quedó entonces "huérfano de la política de partidos" (Ibíd.: 648-654).

Para explicar esta orfandad, entonces, no es suficiente recurrir a las fallas en el rendimiento de los partidos, puesto que, como afirma Torre, el mal desempeño de éstos podría desembocar simplemente en un cambio de gobierno. Entonces, si bien los malos resultados en la gestión se presentan como condición de posibilidad de una crisis de representación, ésta es, en realidad, "el fruto de la existencia de una masa de ciudadanos movilizada en torno de la fiscalización del desempeño de los dirigentes políticos y el cumplimiento de sus promesas electorales" (Ibíd.: 656).

Ante la erosión de las subculturas partidarias, el movimiento de derechos humanos desató un cambio en la cultura política de una importante franja del electorado (el polo no peronista), a partir del cual esta masa de ciudadanos concibió que la relación de representación ya no se sostenía en la identidad entre representantes y representados, y en la consecuente autorización de los primeros por los segundos ${ }^{2}$, sino que dicha relación se basaba en la demanda de rendición de cuentas de los representantes de sus actos y sus promesas (Ibíd.: 656-658). Entonces, es la vitalidad de las expectativas democráticas, la brecha entre éstas y los resultados obtenidos, y un electorado menos comprometido con las lealtades partidarias que demandaba que los gobernantes rindieran cuentas, lo que posibilitó que se impusiera una lectura de la brecha en la cual los partidos (todos ellos) aparecían como los principales responsables.

\footnotetext{
${ }^{2}$ Nótese que aquí la identidad política se convierte en sinónimo de autorización total, es decir, de delegación.
} 
Así, al asumir que la representación es sustancialmente "rendición de cuentas", se excluye la posibilidad de que la identidad política sea algo más que mera autorización. Es decir, se niega la posibilidad de que la representación sea el mecanismo a través del cual se constituyen las identidades políticas (Laclau, $2000,2005) .{ }^{3}$ En pocas palabras, si criticamos esta perspectiva es porque, en primer lugar, la misma asume una relación de pura exterioridad entre representantes y representados y, en segundo término, porque con esta idea se excluye toda posibilidad de que la identidad política sea la fuente de la legitimidad de la representación, es decir, de que la representación no consista en mera delegación sino en la instancia a través de la cual la acción colectiva deviene posible. Pero esto no es posible al interior de esta interpretación, puesto que los supuestos que la sostienen hacen de la identidad un sinónimo de lealtades partidarias, las cuales impedirían el momento del juicio y la evaluación autónoma del ciudadano, que le estaría otorgando así a los gobernantes un "cheque en blanco": la identidad es sinónimo de autorización total y, por ende, de sumisión. Desde nuestra perspectiva, es precisamente la reducción de la ciudadanía a un conjunto de individuos cuya única "participación" es juzgar la gestión post facto lo que impediría que se conformen gobiernos representativos.

Por su parte, Ana María Mustapic comparte con otros analistas la idea de que la crisis de representación es una crisis de los partidos políticos y, ateniéndose a ello, dará cuenta de su doble dimensión: por un lado, la que hace a la relación partidos-sociedad; por el otro, la relación entre partidos y gobierno. Para esta autora los partidos deben ser capaces de reproducir los rasgos de la sociedad, y es precisamente la imposibilidad de hacerlo, es decir, la

\footnotetext{
${ }^{3}$ Como este trabajo no tiene por objetivo el desarrollo teórico y el espacio es reducido, preferimos no extendernos sobre estas cuestiones. Es por eso que nos limitamos a decir aquí que nuestras interpretaciones se sostienen en las premisas del pensamiento político posfundacional (Cfr. Laclau, Lefort, Nancy, etc.), las cuales se encuentran bien analizadas en Marchart (2009). A modo de síntesis, algunas de estas premisas son: a) La necesaria imposibilidad de un fundamento último (de la sociedad, de las identidades) y, por ende, la necesaria contingencia de todos los fundamentos posibles. b) Comprender el momento de "lo político" como el momento de institución ontológica de la sociedad y, en consecuencia, sostener la primacía de lo político respecto de lo social. c) Comprender "la política" como el momento de actualización del fundamento, es decir, la política como un subsistema social particular, como una esfera de actividades especializada donde se ejerce la competencia de partidos y donde se forma y se renueva la instancia general de poder. d) Postular la diferencia entre la política y lo político como una diferencia política y por eso de orden ontológico. Ahora bien, tener en cuenta cada una de estas premisas para pensar la representación política es hacer de ella un momento imposible y necesario a la vez. En franca analogía con el acto mismo de fundar, representar implicará el momento de constitución de una identidad que nunca podrá realizarse plenamente, puesto que se constituye trazando una frontera con aquello que no es, con aquello que excluye. $Y$ es por ello que la representación será siempre estructuralmente incompleta, fallida. Y sin embargo, dicha identidad deberá atravesar el momento representativo para ser. Sostenerse en la paradoja: dar cuenta de que las condiciones de posibilidad son a la vez las condiciones de imposibilidad. Afirmar que "la empiria de lo social" ya no puede ser el único fundamento positivo incuestionable, ya que esa misma empiria está políticamente fundada, significa para la representación terminar con la premisa de la transparencia y del reflejo fiel. Pero el fin de este mito no se debe tanto a una afirmación acerca del carácter opaco de la sociedad y de la política (aunque la incluye), sino más bien a un cuestionamiento más radical acerca de aquello que es representado. Si la transparencia entre sociedad y política, entre representados y representantes, ya no es posible, es porque lo representado no tiene una entidad prepolítica: representantes y representados se constituyen como tales en el mismo acto representativo (Yabkowski, 2010: 68-112).
} 
imposibilidad de articular y agregar intereses sociales, lo que nos sume en la crisis de representación (Mustapic, 2002: 165). Ahora bien, si esto sucede es porque el sistema electoral federal coloca restricciones al surgimiento de nuevas fuerzas que sí sean capaces de reflejar los rasgos e intereses de una sociedad cambiante. ${ }^{4}$ Es decir que Mustapic desarrolla una "teoría del desajuste" entre las instituciones políticas y la sociedad, interpretando el resultado de las elecciones legislativas de octubre de 2001 (ver cuadro 1) como la muestra de las dificultades que el sistema de partidos enfrentaba para adaptarse a las demandas ciudadanas (Ibíd.: 170).

Entonces, por una parte, tenemos los arreglos institucionales que impiden un buen "reflejo" de los rasgos y los intereses de la sociedad. Pero a ello debe sumarse el problema del gobierno, que se sintetiza en los comportamientos que tienen representantes y partidos cuando se encuentran en el poder. Se comprende entonces que una de las dimensiones de la crisis de representación esté asociada al mal desempeño de los gobernantes, que los aleja de la sociedad. Aquí el centro de la explicación se coloca en las formas de funcionamiento y organización de los partidos, pues son estas reglas y prácticas las que estimularían en los representantes un determinado tipo de comportamiento, cuya consecuencia es la conformación de una clase política ensimismada que no puede administrar eficientemente los intereses que representa. ${ }^{5}$ Es decir que Mustapic pone en juego la idea de la cartelización de los partidos (Katz y Mair, 1995) para explicar la crisis de representación, puesto que desde el momento en que su existencia, su reproducción y su supervivencia ya no depende de su vínculo con la sociedad sino de su inserción en el Estado, el sistema cartel de partidos, por un lado, promueve los "malos comportamientos" de los representantes que los alejan de la sociedad y, por otro, conspira contra la existencia de personal idóneo en el aparato estatal, todo lo cual desemboca en una gestión ineficiente. ${ }^{6}$

Lo que observamos entonces es una asociación entre una idea de representación como reflejo de la sociedad y un acento en la dimensión institucional de la crisis. Esta conjunción no es arbitraria, por el contrario, está fundamentada y sostenida en un determinado concepto de política: allí la política se encuentra reducida a las instituciones, y es por ello que su carácter

\footnotetext{
${ }^{4}$ Los partidos nuevos surgen y caen con la misma velocidad debido a que si bien pueden emerger en las provincias más pobladas, no tienen arraigo en las provincias más chicas. El sistema D'Hont, el mínimo de cinco representantes por provincia, el sistema de representación mayoritario en el Senado, todo ello tiene como consecuencia la sobrerrepresentación de las provincias chicas y la subrrepresentación de las provincias grandes. Se obtiene así un efecto bipartidista y mayoritario, a la vez que un esquema institucional favorable a la cartelización (Mustapic, 2002: 171-172).

5 'Los partidos pasan a ser 'confederaciones', 'coordinadoras de comarca' que dificultan la cohesión de los liderazgos nacionales e inciden, por lo tanto, en su capacidad de decisión una vez en el gobierno. En otras palabras, afectan a la gestión eficiente de los intereses sociales que representan" (Ibíd.: 181, cursiva nuestra).

${ }^{6}$ El problema del desempeño en el gobierno como causa de la crisis de representación política es un elemento que también aparece en un artículo de Juan Abal Medina y Julieta Suárez Cao (2002). En éste el acento cae nuevamente en el debilitamiento y desestructuración del sistema de partidos a causa de "la pobre perfomance de los partidos en ocasión de su capacidad gubernativa (...) la sucesión de gobiernos de diferente color que se probaron incapaces de satisfacer las expectativas ciudadanas propicia un aumento de la deslegitimación del régimen in toto" (Ibíd.: 185). Se comprende entonces que en estas interpretaciones que colocan el acento en el mal desempeño la política se torna sinónimo de administración o gestión.
} 
de adecuadas o inadecuadas se juzga a partir de su capacidad para "reflejar" o, a lo sumo, "agregar" los intereses sociales. Para comprender esto un poco más veamos otra interpretación que se sostiene en estos mismos presupuestos teóricos.

Para que la representación funcione, dice Juan Abal Medina (h), es necesario que existan sociedades representables donde los individuos puedan reconocerse como pertenecientes a una parte de la sociedad $y$, por consiguiente, sentirse representados por un partido (Abal Medina, 2004: 52). Por otra parte, son necesarios gobiernos representativos. Esta conjunción es la que permite que la ficción representativa funcione, lo que sucedió cuando en la mayor parte del mundo occidental (Argentina inclusive), luego de la Segunda Guerra Mundial, se consolidaron los partidos burocráticos de masas.

En el modelo de masas (Ibíd.: 69-80) las sociedades generan identidades colectivas fuertes, sólidas, compactas y altamente cohesionadas (subculturas políticas), y los partidos se presentan como la expresión de grupos sociales prepolíticos, de modo que la representación llega a ser el reflejo de la estructura social cuando las elecciones son la expresión de una escisión entre fuerzas sociales en conflicto entre sí. Es decir que entre el juego social y el juego político, cada uno con su propia lógica y sus propias reglas, se presenta una relación de homología estructural: "Una relación de homología estructural significa que la lógica de las relaciones que se dan entre los actores de la sociedad (representados) es equivalente a la lógica de la relación que se da entre los actores políticos (representantes)" (Ibíd.: 78).

Todo ello cambió a partir de la década del '80. La transformación del Estado, a través de sus procesos de desregulación, privatización y descentralización, provocó que los gobiernos ya no pudieran garantizar políticas públicas, perdiendo con ello los partidos sus referentes sociales. Además, deben tenerse en cuenta los efectos de la globalización que implican, entre otras cuestiones, que los grandes procesos económicos y culturales dejan de ser controlados exclusivamente por los estados nacionales. $Y$ a ello se le suma el impacto de los medios de comunicación, que trasladaron la política -dice Abal Medina- del ámbito público al privado (Ibíd.: 81-83). Para el autor, todas estas transformaciones provocaron que la política pierda la centralidad que habría tenido anteriormente. Si esto explica las dificultades que enfrentan los partidos -ya no de masas sino profesionales-electorales (Panebianco, 1995)- para "hacer política", la clave de la crisis de representación se encuentra, en realidad, "en otro lado". Es el sustrato social el que se ha transformado: ante la creciente diferenciación social, las sociedades son más individualizadas y heterogéneas, mientras que las identidades se tornan flexibles, variables y no orgánicas, entendiendo que el correlato político de estos cambios es un voto con menos determinaciones estructurales, más dependiente de la coyuntura y de la imagen personal de los candidatos alrededor de la cual se estructura la campaña electoral (Abal Medina, 2004: 85-89). En síntesis, lo que ha entrado en crisis son las sociedades representables, y si la ficción representativa ya no funciona, se pone en cuestión la forma en la que se legitiman los gobiernos electorales. "Representar lo social parece volverse imposible, pues no hay forma de establecer relaciones homológicas en ese juego fracturado, cambiante, heterogéneo y complejo en el que se ha convertido la sociedad" 
(Ibíd.: 102). No hablamos entonces de una crisis política, sino de una crisis de lo social que tiene sus consecuencias en el plano político.

La opinión pública es ahora, para Abal Medina, el nuevo sujeto a representar. Ella no es simplemente contrapoder sino la principal fuente de legitimación política, y las instituciones deben adaptarse a esta nueva situación para poder reconstruir la legitimidad de la representación. Se trata entonces de inaugurar la representación postsocial, encontrando herramientas institucionales que la fortalezcan, porque "ésta será la clave de la reconstrucción de la legitimidad de la representación" (Ibíd.: 114). La solución pasa así por la creación de mecanismos institucionales de control que le permitan al ciudadano conocer y controlar a sus gobernantes, por abrir ámbitos importantes de la política a los políticos no profesionales (a los ciudadanos) para que puedan hacer un seguimiento de las políticas públicas, promoviendo la participación activa a través de referendum, plebiscitos, consejos ciudadanos, etc., es decir, fomentando aquellos mecanismos donde prime la lógica deliberativa (Ibíd.: 117-122).

En definitiva, la crisis es producto de un desajuste entre las nuevas sociedades irrepresentables y un marco institucional viejo y obsoleto. $Y$ ello porque lo social es aquí el fundamento último de la política.

Aludir de esta manera a las transformaciones sociales implica negar la productividad de la política para dar forma a la sociedad, para instituir identidades políticas, desde el momento en que se asume que la política representativa consiste en un reflejo más o menos fiel de la estructura social. Observamos esto cuando en el modelo de masas se le niega a los actores representados su carácter político, ellos eran "simplemente sociales" y la política transcurría "en otro lado": la homología estructural era posible y operaba como condición necesaria, pero por sobre todo suficiente para el funcionamiento de la ficción representativa. $Y$ al decir suficiente estamos dando cuenta de que, en este argumento, la acción política, como instituyente de los actores qua representados y qua representantes, es negada. De este modo, representantes y representados jugaban cada uno su propio juego, según sus propias lógicas, en el terreno que les correspondía, produciéndose de alguna manera una equivalencia entre ellos.

El problema es que con los supuestos teóricos que sostienen esta interpretación no es posible explicar las razones de esta equivalencia. La única referencia es a una sociedad representable, lo que falta explicar es cómo se convierte esta sociedad en efectivamente representada. Esta falta se explica entonces por la ausencia de una noción instituyente de la política que considere la constitución de identidades como un elemento clave de la representación.

Teniendo esto en cuenta es que sostenemos que en estas interpretaciones la representación sigue siendo de lo social, por más que se le ponga el epíteto de "postsocial", puesto que lo que se plantea es la necesidad de una homología estructural aggiornada, es decir, de un nuevo marco institucional que pueda representar mejor, reflejar mejor, no ya a las distintas subculturas políticas, sino a la opinión pública.

Hemos presentado hasta aquí algunas lecturas sobre la crisis de representación política argentina. Sin embargo, y a pesar de la utilización de 
este término que parece referir a una "situación terminal", las ciencias sociales parecen coincidir en que este fenómeno que se desarrolló durante la década del '90 debe ser leído más bien como una metamorfosis del lazo político (Manin, 1992), es decir, como una transformación estructural y no pasajera de la forma que adquiere una relación que se encuentra en la base de los procesos de legitimación del poder. El término crisis prefiere reservarse así para dar cuenta de otro tipo de fenómeno, más agudo y más puntual, el cual comienza a vislumbrarse con los resultados de las elecciones legislativas de octubre de 2001, tornándose evidente con los acontecimientos de diciembre de ese mismo año. De esta manera, para comprender esta crisis es que resulta necesario referirse a ese proceso de largo aliento, conformado por cambios en la estructura social, en la cultura política, en las instituciones, en los partidos políticos y en la gestión. Cada una de las explicaciones decide así colocar el acento en alguna de estas dimensiones: en el mal desempeño de todos los partidos políticos en la gestión de gobierno, en instituciones obsoletas que no se adaptan a un electorado cambiante o que promueven prácticas indeseables o ya intolerables por los ciudadanos, en una cultura política renovada en la cual la representación es entendida sobre todo como responsabilidad y el deber de rendición de cuentas. ${ }^{7}$ En algunas de estas interpretaciones se apelaba a la cartelización de los partidos, lo cual explicaría, a su vez, la dificultad que tienen las terceras fuerzas políticas para surgir y consolidarse. Teniendo esto en cuenta, podría explicarse el fracaso final del FREPASO y de la Alianza (veremos luego por qué este argumento resulta insuficiente).

Por otra parte, pudimos observar en este corpus de interpretaciones por lo menos dos versiones de una teoría del desajuste: entre las instituciones y la sociedad, por un lado, y entre la nueva cultura política del electorado y las prácticas de los representantes en el gobierno, por otro. También notamos que en las argumentaciones que colocaban el acento en la temática del mal desempeño, la política se convertía en sinónimo de administración. El problema general que encontramos en las teorías del desajuste es que todas ellas suponen que las situaciones "normales" son situaciones armónicas, entendiendo, a su vez, esta armonía como la característica que se hace presente cuando las distintas dimensiones de la sociedad encajan entre sí sin roces ni conflictos. Esta visión seudo-organicista se torna especialmente problemática cuando se trata de comprender los fenómenos políticos, los cuales están marcados por el conflicto. ${ }^{8}$ Creemos que es precisamente esta idea de normalidad que subyace a estas interpretaciones de la crisis de representación lo que les impide observar el papel que juega el conflicto en la conformación de la escena política, ya no en situaciones de crisis sino, precisamente, de "normalidad".

\footnotetext{
${ }^{7}$ Existen otras interpretaciones que no analizamos aquí por una cuestión de espacio y también porque no se centran específicamente en los partidos políticos como las que han realizado Isidoro Cheresky $(1999,2001)$ o Marcos Novaro $(1994,2000)$.

${ }^{8}$ Teniendo en cuenta lo que explicamos en la nota al pie número 3 , podemos decir que es partir del conflicto que se establecen las diferencias, las exclusiones que son necesarias para conformar una identidad política.
} 


\section{Sólo idénticos: discusiones en torno al FREPASO y a la Alianza}

Las discusiones en torno del papel que jugó la centro-izquierda en la crisis de representación resultan ser un campo propicio para el análisis de tal fenómeno, puesto que allí se ponen en evidencia cuáles son los elementos que cada una de las interpretaciones considera más relevante para explicar el fracaso de un intento para restablecer el vínculo representativo erosionado desde los años 90 .

Consideremos en primer lugar el trabajo de Marcos Novaro y Vicente Palermo, Los caminos de la centroizquierda. Dilemas y desafíos del Frepaso y de la Alianza, que tiene la particularidad de haber sido publicado en 1998, es decir, no sólo antes del triunfo de la Alianza en las elecciones de 1999, sino también antes de que la crisis de representación se evidenciara silenciosamente en octubre de 2001 y sonoramente en diciembre de ese mismo año. En este sentido, podría pensarse que ese trabajo corre con una desventaja respecto de aquellos otros que, por una razón de temporalidad, pueden realizar una lectura retrospectiva del papel del FREPASO y de la Alianza a luz de lo que finalmente ocurrió, de modo que compararlos a todos entre sí sin tener esto en cuenta podría resultar, al menos, injusto.

Sin embargo, si perseveramos en esa comparación es porque sostenemos que los autores del trabajo que mencionamos han tenido la habilidad para percibir los rasgos potencialmente problemáticos de estas fuerzas políticas, y si éstos han sido minimizados en relación con esos otros elementos que habilitaban cierto optimismo, no se debería solamente a la imposibilidad de ver a futuro, sino, sobre todo -ésta es nuestra hipótesis-, a una postura teórica sobre la representación que impide comprender el fracaso del vínculo.

El trabajo de Novaro y Palermo se guía por la pregunta acerca de las razones del éxito de la centroizquierda, y sostiene que no sería una situación de pura desarticulación política y crisis institucional la que explicaría tal éxito, sino que, por el contrario, habría que referirse a la consolidación de las instituciones democráticas y del sistema de partidos. Entonces, debe comprenderse, por un lado, que la consolidación democrática propició el marco de inserción institucional del FREPASO, mientras que, por el otro, la crisis que sufrían en particular los partidos tradicionales (y no el sistema en sí) generó el espacio disponible para instalarse electoralmente. Teniendo esto en cuenta, la situación descripta funciona como condición de posibilidad, es decir, como condición necesaria pero no suficiente para el éxito de la centroizquierda, y es por ello que para Novaro y Palermo es necesario referirse a los elementos que permitieron sacarle provecho a la coyuntura: la imaginación y las prácticas de los líderes (Novaro y Palermo, 1998: 16-17).

Entonces, en primer lugar, para los autores hay que considerar que la consolidación de las instituciones democráticas implica la apertura de la competencia interpartidaria, el monopolio partidario de la representación y la adaptación exitosa de los partidos a una nueva situación (Ibíd.: 26-29). Es decir, aquellas interpretaciones que enfatizan el debilitamiento de los partidos para explicar el éxito del menemismo les resultan insuficientes, por lo que sostienen que debe tenerse en cuenta "un proceso que involucra la reorganización institucional y la conservación, y aun reactivación, de los recursos identitarios" (Ibíd.: 35), lo cual es especialmente relevante en el caso 
del Partido Justicialista, que a partir de la Renovación abandonó su carácter movimientista para democratizarse internamente, siendo la institucionalización el mayor aporte de esta corriente a la consolidación del sistema de partidos argentino (Ibíd.: 47).

En segundo lugar, habría que considerar una nueva forma de relación entre los partidos y los actores sociales, a partir de lo cual el FREPASO no se redujo a ser un "catálogo expresivo de las protestas sociales y sectoriales" (Ibíd.: 99), sino que construyó su identidad a partir de la interacción e influencia recíproca con la opinión pública y los electores. Ésta es una de las claves de la interpretación de Novaro y Palermo, puesto que al considerar la protesta social como una serie de "estallidos" de carácter efímero, sin organización ni conducción, como "expresiones de violencia anómica", en muchos casos, de raíz clientelar y carácter antipolítico (Ibíd.: 74-75), resulta imprescindible que el partido se despegue de ella si quiere constituir una identidad política. Hay entonces aquí una lectura del mundo social como un mundo heterogéneo y desarticulado, en el cual las redes clientelares se debilitan en favor de la expansión de la opinión pública, lo cual habilita el desarrollo de comportamientos políticos orientados por el juicio de los resultados, de modo que la política se legitima ahora por su eficacia cotidiana (Ibíd.: 75-76).

Es decir, el FREPASO se constituyó como un partido más representativo porque no había una identidad política preexistente, sino que la instituyó a partir de la relación con una ciudadanía activa que necesitaba la política para expresarse, puesto que de otra forma quedaba reducida a una heterogeneidad desarticulada. De este modo, la política se presentó bajo la forma de liderazgos fuertemente representativos -que daban forma a lo representado-, siendo precisamente los líderes los que definían el contenido de la representación. No había entonces ni identidad preexistente ni mandato concreto, sino que los líderes del FREPASO recibieron de esta ciudadanía una "delegación de capacidad decisoria a partir de una promesa verosímil de 'salvación'", verosimilitud que provenía de una autoridad política basada en la fuerza de los vínculos construidos con las propias señas de identidad (lo cual implicaba que la delegación no era un simple "cheque en blanco", sino que era un vínculo "llamativamente programático") (Ibíd.: 22-24).

Novaro y Palermo explican de esta manera cómo la política performa e instituye identidades políticas, quedando esto demostrado cuando el heterogéneo mundo social es articulado por liderazgos personalistas, puesto que allí se evidenciaría el carácter activo del líder como representante y como decisor (Ibíd.: 70-71).

El éxito del FREPASO se explicaría, así, porque ya había en la sociedad una corriente de opinión, comprometida con ciertos valores, que proveyó los principios de reconocimiento, de modo que lo que hizo esta fuerza política fue suplir una vacancia, lo cual fue posible gracias a los discursos y las acciones innovadoras de sus líderes (Ibíd.: 131-133). Se considera entonces que si bien no había una identidad fuerte, permanente y articulada, sí existía un movimiento más difuso a la espera de ser representado políticamente, disponible. EI FREPASO vino a llenar un espacio vacante y a dar forma a esa corriente de opinión difusa. De ahí que se diga que esta "nueva política" sea más representativa que identitaria, con menos recursos organizativos, pero 
más personalizada (Ibíd.: 258-259). ${ }^{9}$ Su carácter representativo explicaría, a su vez, el surgimiento de la Alianza, puesto que el mismo no fue algo que ni radicales ni frepasistas habían calculado, sino que era lo que la opinión pública estaba esperando: "Puede decirse que eso le pasa a todos los políticos que son representativos e innovadores: son protagonistas de acciones que no les pertenecen, de las que no son autores exclusivos y cuyos significados y resultados se les escapan" (Ibíd.: 182).

Ahora bien, cuando los autores afirman que el FREPASO es "más representativo" lo hacen por oposición a lo identitario. De este modo, consideran la representatividad como el efecto de un vínculo construido políticamente, mientras que la identidad tendría un carácter más esencialista y, por ende, preexistente al lazo político. Pero a la vez hablan de la constitución de "identidades políticas", de modo que podríamos deducir que hay identidades que son representativas (como la que instituyó el FREPASO) y otras que no lo son. Estas últimas serían entonces las propias de los partidos más tradicionales y, en especial, la del peronismo. De alguna manera, Pousadela parece estar de acuerdo con esta oposición cuando describe los rasgos del nuevo formato de representación que se consolidó durante la década del '90, afirmando que la ciudadanía tiene comportamientos "más reflexivos y menos identitarios" (ver nota al pie 14). Resulta interesante esta oposición, puesto que allí se deja traslucir un supuesto según el cual aquello que es más representativo (identidades, comportamientos, liderazgos) es, por ello mismo, más político, mientras que lo que se describe como identitario sería "más social", más naturalizado, menos reflexivo, más permanente y más coercitivo, en definitiva, menos político. De esta manera, lo que se pone en juego aquí es una noción de identidad vinculada a los parámetros organicistas durkhemianos. Sin embargo, y como ya observamos, se utiliza la idea de identidades políticas y representativas para hablar del FREPASO, como también es común escuchar mencionar que las identidades son, en la actualidad, volátiles. A nuestro entender, esto no invalida nuestra observación, sino que da cuenta de la necesidad de adjetivar el sustantivo "identidad" cuando se le quiere otorgar otro sentido. $Y$ es por ello que cuando no se encuentra acompañado de alguna otra palabra, cuando se habla de la identidad "a secas", en su forma "más esencial" adquiere estos rasgos organicistas y pre-políticos que mencionábamos. Si tenemos en cuenta que esta oposición entre representación e identidad es generalmente utilizada para dar cuenta de las transformaciones que se sucedieron desde el retorno a la democracia, podemos asociarla a la oposición que realiza Isidoro Cheresky entre ciudadanía y pueblo (2001), donde la primera tendría un carácter más político que el segundo. Teniendo en cuenta esto último, y todo lo anterior, deberíamos decir que el problema de estas interpretaciones no es tanto la asunción de una noción esencialista y positivista de identidad (por el contrario, y como ya vimos, se encargan de contrarrestar esta idea), sino el prejuicio de que las identidades, antes de 1983, no eran (tan) políticas, lo que llevaría a afirmar que la identidad peronista no fue

\footnotetext{
${ }^{9}$ Esta nueva política se caracterizaría por "la mayor transparencia en la mediación entre líderes $y$ votantes, una menor densidad y opacidad organizativas $(y$, en contrapartida, una mayor personalización de la responsabilidad), la presencia menos dominante de los componentes ideológicos y un mayor pragmatismo, un menor peso de las dimensiones identitarias y uno mayor de las representativas, vínculos de confianza más fundados en la eficacia de la gestión y la acción del político y menos en la movilización" (Novaro y Palermo, 1998: 258-259).
} 
políticamente construida, y/o que los ciudadanos peronistas no necesitaban de la política para expresarse.

Continuando, la opción por un perfil que los autores denominan "republicanismo social modernizador" (Novaro y Palermo, 1998: 103) responde, por un lado, a una corriente de opinión pública "con una matriz ideológica progresista", y por otro, a la necesidad de diferenciarse de un "caudillo populista exitoso" (Ibíd.: 256) -aunque, como ya veremos, estas referencias resultan necesarias pero insuficientes para explicar la elección de este perfil-, observando con esto que el FREPASO sólo pudo construir su diferencia política en el aspecto moral (Ibíd.: 111), formulando una promesa vinculante en torno al fortalecimiento de las instituciones (Ibíd.: 231). Novaro y Palermo reconocen entonces que esta forma de interpretar el cansancio moral de la ciudadanía puede derivar en el qualunquismo, es decir, en una opción de derecha que clausura la política. Pero si el FREPASO no sucumbió ante esta tentación fue porque el carácter representativo de la fuerza no subsume la relevancia de la innovación política de los líderes, que fue precisamente lo que decidió la orientación republicana y evitó el desenlace antipolítico (Ibíd.: 257).

Teniendo en cuenta cómo se ha desarrollado el argumento hasta aquí, debemos observar ciertos cambios en el sentido de la idea de representación. En el comienzo, se destacaba de esta relación política su carácter performativo e instituyente, puesto que no había identidad política preexistente que le impusiera una forma. Por el contrario, la importancia de los liderazgos personalistas dentro del FREPASO era la muestra del carácter activo instituyente, creador, performativo- de la política. Sin embargo, hacia el final del argumento el carácter representativo de este partido de la "nueva política" se transformó en sinónimo de lo que la corriente de opinión, que ya existía en la sociedad, le imponía a los representantes y determinaba, así, el surgimiento de la Alianza. De esta manera, comienza a diluirse el papel protagónico e instituyente de los líderes, puesto que sus acciones y discursos parecen estar siempre determinados por algo más: por un lado, se aduce que la opción por el perfil republicano provino de una sociedad ya cansada moralmente; por otro, el abandono de los motivos movimientistas que todavía permanecían en el discurso se explicaría porque resultaban incompatibles con su función institucional (Ibíd.: 122). Por otra parte, se afirma que el peligro qualunquista fue disipado gracias a la capacidad de innovación de los líderes, pero unas líneas más adelante parece sostenerse lo contrario cuando se refiere, nuevamente, al carácter representativo:

Incluso cabe advertir que un ingrediente qualunquista podría aflorar con alguna fuerza a medida que el FREPASO ya no compite solamente por votos de las clases medias instruidas, sino también por el electorado de clases mediasbajas (portador con frecuencia de una difusa ideología "autoritaria-populista"), que hasta hace poco adhería fervientemente al menemismo. (...) Pero ello no es forzoso. En contra juega no solamente el talento político de los dirigentes del FREPASO, sino la fuerza vinculante de la promesa que los hace representativos de las corrientes sociales progresistas y republicanas (Ibíd.: 258). ${ }^{10}$

\footnotetext{
${ }^{10}$ En estas líneas podemos observar no sólo una noción de populismo que subraya su carácter autoritario adverso a la libertad, sino también cómo los "peligros" provienen de intentar ampliar 
Teniendo esto en cuenta, podemos decir que es esta idea de la representatividad -en la cual se diluyen los elementos performativos- lo que explica que en el argumento de Novaro y Palermo termine predominando, aun a su pesar, la hipótesis de la vacancia por sobre la de la innovación. Es decir, para explicar el éxito del FREPASO se presentaban dos hipótesis, a primera vista complementarias entre sí: la primera aludía a que el partido vino a suplir una vacancia dentro de la oferta política, mientras que la segunda daba cuenta de que la innovación de los líderes permitió que esta operación fuera llevada cabo de forma exitosa. Sin embargo, a medida que el argumento se desarrolla predomina la primera de las hipótesis y se soslaya la segunda, lo que implica al mismo tiempo que la noción de representación pierda su potencia performativa e instituyente. Ésta es precisamente la razón por la cual se desestiman los efectos de una diferencia política construida solamente en el aspecto moral. Es a partir de aquí que afirmamos que ha sido la centroizquierda del FREPASO y de la Alianza la que ha contribuido a forjar el panorama de la indistinción que produjo la crisis de representación.

En otros términos, pero en este mismo sentido, Pousadela explica que el problema de la Alianza ya estaba en su propia gestación, desde el momento en que sus dirigentes optaron por el consenso sobre las reformas estructurales neoliberales y sólo se diferenciaron enfatizando en el comportamiento político, de modo que su triunfo en las elecciones de 1999 puede ser interpretado más como una alternancia que como una alternativa. Lo que quedó ocluido así es el sentido fuerte, instituyente de la política (lo político), a expensas de su sentido más débil (Pousadela, 2003).

El problema del análisis que realizan Novaro y Palermo no se debe entonces a una desventaja producida por una cuestión de temporalidad, sino a la desestimación de los efectos que tiene para una identidad política la falta de uno o varios conflictos propiamente políticos a partir de los cuales constituirse. Lo que se desatiende entonces es la importancia de un sistema de alteridad. Esta dimensión es la que retoma Beatriz Alem (2007) para explicar que el FREPASO constituyó una identidad lábil y reactiva, es decir, como pura reacción ante un escenario ya determinado. La lucha ideológica constitutiva que implica tomar una posición acerca de los asuntos públicos (es decir, posicionarse dentro de un campo de conflictividad y contribuir a formarlo como tal) fue reemplazada por una presentación de las diferencias en el espacio mediático, lo que contribuyó a una definición meramente negativa de lo que el FREPASO era. Esta primera dimensión de heterogeneidad es necesaria en la constitución de toda identidad política, pero se requiere también la dimensión de la homogeneidad, del "quiénes somos", la cual nunca estuvo presente más allá de una valoración moral en términos de la palabra empeñada. De este modo, Alem comparte con Novaro y Palermo la centralidad que adquiere en el análisis el tema de la constitución de las identidades. La diferencia radica en que, mientras para ellos la representación de una vacancia en el mercado de los partidos políticos parece resultar suficiente, para Alem eso no resulta ser lo

la representación a las clase medias-bajas, siendo las clases medias instruidas, progresistas y republicanas las que nos protegerían contra ello. De alguna manera, se está reproduciendo aquí ese sociologismo electoral que critica Yann Basset (2003), puesto que sería la falta de instrucción lo que explicaría la tendencia antirrepublicana y anticívica. 
más importante. Y ello porque la corriente de opinión pública -aquella que ya existía en la sociedad, según los autores- no es un sujeto a representar, de modo que refractarse en el espejo de los sondeos no permite constituir un modelo de subjetividad política ${ }^{11}$, ya que así el FREPASO sólo puede ver la imagen de lo que es viendo la imagen de aquel que le da origen (la agenda periodística, "la gente"), pero no su propia imagen como "otro", distinto, diferente, que puede leer el estado de opinión y construir su identidad en diálogo con él, por referencia a él, pero no mimetizándose acríticamente con él, o con la imagen de él que él le muestra y que es el resultado de la aplicación de un conjunto de instrumentos altamente problemáticos (Alem, 2007: 264).

Resignarse así a "escuchar a la opinión pública" implica "transmutar el lugar de los actores en la política" (Ibíd.: 266), contribuyendo de esta manera a deslegitimar el trabajo que es propio de la política.

Si adscribiéramos a la idea de representatividad que proponen Novaro y Palermo, deberíamos decir que fue precisamente el carácter fuertemente representativo del FREPASO el que impidió restablecer una comunidad a partir de la cual los ciudadanos pudieran reconocer un vínculo con sus representantes, puesto que la identidad se tornaba al mismo tiempo indistinción. En cambio, si retomamos una noción de representación en la cual los clivajes, las divisiones y las diferencias propiamente políticas resultan centrales para constituir una identidad política, y una comunidad entre representados y representantes, deberíamos decir que el FREPASO y la Alianza contribuyeron a producir la crisis de representación política al fracasar en constituirse como "otro".

\section{La indistinción política: el fin de la comunidad}

Teniendo en cuenta estas críticas, es que ahora expondremos aquellas lecturas de la crisis de representación que entienden que la constitución de identidades políticas necesita de la creación de clivajes, pues son los conflictos los que permiten establecer las diferencias, es decir, las divisiones que crean comunidad. ${ }^{12}$ Establecer un lazo de comunidad entre dirigentes y ciudadanos

${ }^{11}$ Como propone Gabriel Vommaro, políticos, periodistas y encuestadores contribuían a fortalecer la idea acerca del carácter transparente del sondeo, anulando con ello todo rasgo de opacidad de la política, lo que permitiría una medición exacta y adecuada. Carlos "Chacho" Álvarez era uno de ellos, lo que podría demostrarse cuando aduce que es necesario "sincerar ideológicamente (y también socialmente) la política argentina", "corrigiendo" las "distorsiones" históricas de los alineamientos políticos (Página 12, 10 de agosto, 1997, citado en Novaro y Palermo, 1998: 199). Novaro y Palermo, teniendo en cuenta estas frases y otras que aparecen en documentos del FREPASO y declaraciones públicas de sus dirigentes, dicen al respecto: "La finalidad del argumento es justificar la necesidad de atraer a la Alianza a los peronistas desencantados con Menem. Esta finalidad puede ser muy plausible, pero el argumento conspira evidentemente contra los principios básicos del Frente y es francamente insostenible" (1998: 208). El problema que hallamos aquí es que, a nuestro entender, esto no sólo no va en contra de los principios del Frente, sino que además está en consonancia con la idea de representatividad que sostienen los autores, puesto que la idea de un "sinceramiento" se condice con cierta idea de transparencia invocada cuando se refieren al enraizamiento del FREPASO en una corriente de opinión pública ya existente en la sociedad.

${ }^{12}$ Para comprender por qué las divisiones crean comunidad nos podemos referir a los trabajos de Jean-Luc Nancy, según el cual la comunidad es siempre inoperante. Ello quiere decir que la comunidad no se funda en lo común, sino más bien en el espacio "entre". En consecuencia, los 
no implica entonces desconocer la separación que la representación política supone, sino reconocer esa brecha en la cual el trabajo de la política imposible y necesario- tiene lugar. Se trata de exponer aquí aquellas lecturas que suponen que hay representatividad cuando hay comunidad, es decir, cuando hay división, conflicto, política. El lugar que aquí se le otorga al conflicto es entonces uno de los elementos distintivos que en aquellas otras interpretaciones había quedado, por lo menos, relegado. El otro elemento es la palabra: comprender qué ha sucedido en esos años con la palabra política será central para dar cuenta tanto de los procesos de identificación como de los procesos de deslegitimación y descrédito de los representantes.

Comencemos entonces por un trabajo de Edgardo Mocca (2002), quien, al comprender que no es suficiente referirse solamente a la insolvencia de los políticos y los partidos, analiza, precisamente, qué ha sucedido durante los ' 90 con la retórica política. Mocca observa así la expansión de una retórica antipolítica que atraviesa transversalmente clases sociales y posiciones ideológicas, presente también, y especialmente, en la serie de discursos de muchos miembros de la "clase política" que dicen ser, ellos mismos, parte de "la nueva política". Esta adscripción a lo nuevo no se realiza en base a una diferencia política o ideológica con otros miembros de su "clase", es decir, tomando posiciones respecto de conflictos que involucran a los ciudadanos, sino que, por el contrario, su diferencia consiste en tener una conducta distinta al interior de esa clase que fue descalificada en su conjunto.

Mocca explica que el discurso antipolítico se enfoca en "lo que la política 'no debe ser' y tiende a diluir lo específicamente político en imperativos propios de terrenos sociales vecinos: la economía, la ética, la ideología, la sociedad civil" (Mocca, 2002: 261). De este modo, lo propiamente político desaparece, y las críticas políticas a los políticos no figuran en escena, sino muchas otras de índole distinta. Teniendo esto en cuenta, se puede explicar, por ejemplo, cómo la economía ha ganado gran terreno a expensas de la política, reduciendo todo problema argentino a una cuestión económica, abordable solamente a través de saberes técnicos y profesionales. La deslegitimación que ha sufrido entonces la práctica política explicaría gran parte del proceso que desemboca en la crisis de representación. Algo similar ha sucedido con el campo de la ética. Las claves de interpretación política de la realidad y sus actores han sido desplazadas por otros criterios cognitivos que privilegian la división entre honestos y corruptos, deslegitimando no sólo cualquier adversario político, sino la lucha política misma. Mocca reconoce que esta dimensión de la retórica antipolítica se encuentra presente en los discursos del ARI, a la vez que ha

lugares desde los cuales las singularidades se comunican entre sí constituyen, antes que el espacio de una fusión, el de una dislocación, y por ello las relaciones que son constitutivas de la comunidad son, a la vez, constitutivas de una ruptura. Si el verbo que se hace carne en la comunidad es partager, es porque con él la lengua francesa da cuenta, al mismo tiempo y sin contradicciones, del doble sentido de compartir y dividir: "toi partage moi", decía Nancy (2000: 58). Teniendo esto en cuenta, la emergencia de la comunidad es un acontecimiento, es el momento del acontecer, estructuralmente inesperado, incalculable, razón por la cual crea (se basa en) la discordia, el conflicto. También nos sostenemos en los trabajos de Jacques Rancière (1996), para quien la comunidad política aparece como tal cuando se introduce un litigio, una distorsión acerca de la cuenta de sus partes, cuando esa cuenta es siempre errónea porque lo que ha emergido es la parte de los sin parte. 
sido el eje de la construcción de la figura de "Chacho" Alvarez, antes del fracaso estrepitoso de la Alianza.

Concluye entonces Mocca que, sin desconocer los obstáculos de índole técnica, burocrática, de saberes específicos necesarios para la gestión, debe comprenderse que los problemas que enfrenta la política argentina (luego del 2001) son propiamente políticos. Es decir, su capacidad para crear agendas y establecerlas, para trazar prioridades, generar consensos en base a un amplio debate público, en definitiva, la capacidad para interpretar la realidad, crearla y transformarla en base a lo que se concluya de una lucha propiamente política. Es por ello que Mocca sostiene que la sola reforma de la ingeniería institucional no puede solucionar estos problemas. Se trata, más bien, "de recuperar el sentido de lo público en el reino de la fragmentación y la anomia” (Ibíd.: 285).

Observamos en este trabajo que la retórica es entendida como parte constitutiva del hacer de la política, dejando atrás la distinción entre "meros discursos" y acciones "concretas". De este modo, la crisis de representación es política, porque lo que ha entrado en crisis es la palabra política. ${ }^{13}$ El quiebre de la confianza debe entenderse entonces a partir de la extensión de una retórica antipolítica que impugna, incluso, a los mismos que la pronuncian. Ahora bien, las palabras no son políticas simplemente porque las enuncie un miembro de la clase dirigente. De otro modo, deberíamos comprender que sólo la función pública o partidaria habilita tales discursos. En este sentido, la expropiación de la palabra no fue sufrida solamente por los ciudadanos reducidos a electores-espectadores, sino también por los representantes. Es por ello que una de las posibles interpretaciones del "que se vayan todos" refiere a la necesidad de recuperar una palabra política perdida.

Con esta lectura se pone en el centro la necesidad de referir al discurso a través del cual se interpreta, por ejemplo, el mal desempeño. $Y$ si bien es cierto que Torre parecía encarar este camino, al no tener en cuenta la dimensión retórica de la política no podía dar cuenta de aquello que había entrado en crisis. Dicho en nuestros términos: la desaparición de la palabra política es lo que impide la identificación de los ciudadanos con sus representantes, puesto que el trabajo político de cerrar esta brecha entre unos y otros resulta imposible cuando la in-diferenciación se torna la regla.

Para dar cuenta entonces de la indistinción como elemento clave de la crisis de representación, retomamos los trabajos de Inés Pousadela, quien analiza el fenómeno teniendo en cuenta la diferencia entre metamorfosis y crisis. A partir de aquí, entiende que el nuevo formato de representación que se gestó desde $1983^{14}$ tuvo una serie de efectos, especialmente sobre los partidos políticos,

13 Una interpretación similar es la que realiza Eduardo Rinesi (2007), quien entiende que la palabra política entró en crisis en la Semana Santa de 1987, cuando el presidente Alfonsín envió a los manifestantes "de vuelta a su casa", lo que generó la idea de que éste había negociado "en secreto" con los militares sublevados.

14 Los cambios que se han producido desde 1983 en el sistema representativo asumen dos direcciones: por un lado, ha variado la composición de la "oferta electoral", y por el otro, las preferencias de los ciudadanos fluctúan de una elección a otra, y la ciudadanía tiene comportamientos más reflexivos, más complejos y menos "identitarios", sus decisiones son cada vez más individuales, y dependen de una gran variedad de factores, entre los cuales se sigue incluyendo la pertenencia partidaria de un candidato, aunque ha dejado de tener el peso que antes se le atribuía. Los medios de comunicación han pasado de ser trasmisores de la política a ser el espacio donde la política tiene lugar. Así es que se producen nuevos liderazgos 
que produjeron un terreno fértil para el desencadenamiento de la crisis, definida como "la falla en el lazo representativo por ausencia de reconocimiento de ese vínculo por parte de los propios representados: si bien los representantes son de hecho representantes -se constituyen como tales según los procedimientos establecidos, son legitimados mediante elecciones- no son, sin embargo, suficientemente 'representativos'" (Pousadela, 2004: 129). Así, si no hay reconocimiento del vínculo, el vínculo como tal desaparece, de modo que lo que se rompe es lo que nosotros denominamos el lazo de comunidad entre dirigentes y ciudadanos. La pregunta es por qué se produce esta ruptura.

Para explicar esto la autora recurre a la noción de "partidos cartel" de Katz y Mair (1995), puesto que con ella se da cuenta de una situación donde todos los partidos son gobierno en uno $u$ otro nivel, reduciéndose de este modo la competencia y la obligación de rendir cuentas antes los representados. Si la explicación terminara aquí, Pousadela no estaría diciendo algo muy distinto a Torre o, incluso, a Mustapic. Sin embargo, esto no es así porque en su explicación se retoma también la crítica a la "clase política" que parece formar parte de todo proceso de crisis de representación, la cual nos muestra lo siguiente: por un lado, la ciudadanía percibe que "son todos ladrones" -lo cual debe ser comprendido teniendo en cuenta la dimensión ética de la retórica antipolítica que analizaba Mocca. Por otra parte, el electorado cree que "son todos iguales".

Y en este último punto se encuentra la clave. Al ser todos los representantes iguales no hay posibilidad de distinción, de diferencia, de división: el consenso entre los propios partidos impide así reconocer el vínculo que da lugar a la representación, porque dicho consenso anula la comunidad política. Si no hay diferencias que dividan no hay partes, y sin partes no hay todo, no porque la totalidad sea el resultado de una simple suma aritmética, sino porque el consenso es el nombre del borramiento de esas fronteras que trazan el adentro de la comunidad.

En resumen, lo que estamos proponiendo aquí es que la representatividad es un vínculo que necesita ser reconocido, y para que ello se produzca es imperativo que exista una comunidad al interior de la cual dicho vínculo pueda desenvolverse. Pero la idea de comunidad que aquí se expone no tiene su referencia en "lo común" o, mejor dicho, en una idea de lo común como consenso. Por el contrario, sostenemos que hay comunidad cuando hay un conflicto a partir del cual se establece (por lo menos) una frontera que produce una división, porque es precisamente esa frontera la que marca que hay un

mediáticos, por fuera de las estructuras partidarias, que generan su apoyo en base a los lazos de confianza con la opinión pública, pero que carecen de implantación territorial y una estructura organizativa sólida, lo que les obstaculiza su permanencia en el tiempo y su consolidación. Aún más, su propio discurso es el que incentiva una ciudadanía más autónoma, lo que finalmente termina perjudicándolos en sus proyectos de largo plazo, pues no tienen capacidad de conformar una base de apoyo sólida y más o menos estable, exponiéndolos de esta manera a lo que se denomina el "trasvasamiento no tutelado de los votos". Mientras que los partidos más antiguos comienzan a adoptar estrategias más pragmáticas, debilitando los requerimientos para la pertenencia e identificación, para así convertirse en estructuras más flexibles y adaptables (Pousadela, 2004: 125-128). Dicha caracterización se sitúa desde mitad de la década del 80 hasta los primeros años pos crisis de 2001. Teniendo en cuenta las transformaciones que se sucedieron en los últimos diez años, será parte de otro trabajo analizar las rupturas y las continuidades en el sistema representativo. 
espacio de representación en el que confluimos como diferentes. Dicha división no sería entonces sinónimo de fragmentación o de anomia, sino de lazo político. Somos parte de una comunidad que lucha por representar el todo. He ahí la política. Ahora bien, cuando no existen o se soslayan los conflictos que contribuyen a trazar esas fronteras que instituyen la comunidad política, la indistinción y el consenso no hacen sino diluir las condiciones de posibilidad para que el vínculo representativo se genere.

Veamos ahora cómo pueden interpretarse los resultados de las elecciones de octubre de 2001 a la luz de lo que acabamos de exponer. Yann Basset (2003) entiende, en primer lugar, que tanto el voto nulo (12,5\% de los votos válidos) como el voto en blanco (9,4\% de los votos válidos) y el abstencionismo $(27,2 \%)$ son formas de expresar el descontento (y no que responden a una carencia de civismo). Hay quienes comprenden estos resultados enfatizando el "voto castigo" ante la difícil situación económica y social, mientras otros estiman que fue un "voto ético" como protesta contra la corrupción. Sin embargo, aunque el autor reconoce que ambas dimensiones son la base del "voto bronca", falta explicar aún por qué el voto castigo-ético se canalizó hacia el voto negativo y el no voto, puesto que el castigo podría haberse manifestado a través de un crecimiento electoral de la oposición, mientras que la posición anti-corrupción podría haberse expresado con un caudal de votos dirigido hacia aquellos partidos que hicieron de este tema su bandera. ¿Qué fue entonces lo que provocó que el descontento se expresara a través del voto negativo y el abstencionismo?: "fue la ilegibilidad del campo político-electoral y, en particular, la casi desaparición de la frontera oficialismo/oposición que dio la impresión de irresponsabilidad y que alentó al prejuicio del 'son todos iguales"' (Basset, 2003: 69).

Así, los políticos que decían ser parte de la "nueva política" (especialmente el FREPASO y la Alianza) contribuyeron a forjar este panorama de la indistinción y de la ilegibilidad con su retórica antipolítica, por un lado, y con su consenso sobre las reformas estructurales neoliberales, por otro. Pero a esto también contribuyó el uso político de los sondeos de opinión pública, ampliamente extendido durante la década de los '90 (y hasta la actualidad). Gabriel Vommaro, quien ha trabajo al respecto, afirma que en las encuestas tienden a perderse los clivajes políticos y las divisiones sociales en pos de un pueblo uno, "la gente", al que sólo puede pensarse separado por porcentajes (...) "la gente" como sujeto evanescente, irrepresentable políticamente o, mejor dicho, sólo representable como realidad homogénea, cosificada, borrando toda posibilidad de constituir clivajes políticos, sociales y culturales que crearan un vínculo colectivo (Vommaro, 2003: 113).

La UCR y el FREPASO primero, y la Alianza después, sufrieron precisamente esta falta de comunidad generada en la indistinción, y si no pudieron contra ella es porque contribuyeron a reforzarla. Desestimaron los efectos que tiene para una identidad política la falta de uno o varios conflictos propiamente políticos a partir de los cuales constituirse como "otro". Es decir, desatendieron la importancia que tiene un sistema de alteridad política (y no solamente moral).

Esta interpretación a la que adscribimos acerca de las razones del fracaso del FREPSASO y de la Alianza implica, de alguna manera, afirmar que lo que se ha erosionado $-\mathrm{y}$ debe ser reconstituido- es la idea del partido como parte (Sartori, 1992), puesto que es en tanto parte que puede forjar su identidad a 
través de las palabras, los conflictos y los clivajes, es decir, a partir del establecimiento de la diferencia sin la cual no hay identidad. Si la crisis de representación es de los partidos, lo es en este preciso sentido. Pero debe comprenderse que ello no implica negar el carácter hegemónico de la política (Laclau y Mouffe, 2004), por el contrario, se trata de revalorizar al partido como la forma institucionalizada que adquiere una parte de la sociedad que siempre intentará representar la totalidad, aunque ello resulte constitutivamente imposible.

\section{Las jornadas decembrinas de 2001: un momento político}

Teniendo esto en cuenta, podemos avanzar en una interpretación de las jornadas de protesta del 19 y 20 de diciembre de 2001, como la expresión más álgida de la crisis de representación.

Durante las jornadas de protesta se produjo una suspensión temporaria de las identidades sociales previas (Giarraca, 2003) a la cual nuestros entrevistados se refieren mediante la descripción del suceso como una "fiesta" o un "carnaval". El uso del término no es ocioso, ya que hace referencia, al igual que en el discurso de la antropología, a una situación liberadora, una suerte de "tiempo fuera del tiempo", un momento de desorden trasgresor en el cual son temporariamente suspendidos las reglas y códigos conocidos (Pousadela, 2007: 12).

Asumiendo ese carácter trasgresor que implicaba la suspensión temporaria de las reglas y los sentidos instituidos, no resulta un dato meramente coyuntural o accesorio el hecho de que los cacerolazos comenzaran a escucharse mientras el todavía presidente De la Rúa anunciaba por cadena nacional la implantación del estado de sitio. Si bien es cierto que, como explica Cheresky, la reacción puede entenderse a partir de la existencia de un ciudadano que se concibe a sí mismo sobre todo como sujeto de derechos, que lleva la impronta de los cambios que los organismos de derechos humanos produjeron en la cultura política (Cheresky, 1999, 2001, 2006), a ello parece necesario agregar otras interpretaciones.

En efecto: el estado de sitio no era solamente la expropiación de un derecho (aunque esta expropiación no fuera poca cosa): era también la consagración de la separación entre representantes y representados, puesto que ya no eran los primeros los que resultaban obligados por los segundos, sino exactamente al revés. Desde la televisión, el máximo representante pronunciaba las palabras con las cuales se expropiaba la palabra de todos los espectadores-ciudadanos, constituyéndose así dicho discurso en la muestra más odiosa del "hacer cosas con palabras" que nos enseñara Austin (2003). Pero no funcionó, porque para que la palabra impusiera concretamente el estado de sitio era necesario que existiera una comunidad de sentido. Quienes "naturalmente" ("policialmente", diría Rancière) debían ser meros espectadores televisivos y, a lo sumo, opinión pública reflejada en las encuestas, irrumpieron en el espacio público de otra manera. El cuerpo presente era entonces un dato nuevo, o por lo menos, relativamente nuevo para un sector importante de la población. Es decir, no hace falta recurrir a la intención individual de cada ciudadano que bajó espontáneamente a su puerta, luego fue hasta la esquina y de ahí hasta la Plaza de Mayo, para determinar el carácter político de ese momento. Puesto 
que aun quienes marcharon creyendo sinceramente que "lo deseable" era que no hubiera más política ni más políticos, estaban participando de un fenómeno que no sólo los excedía -y que, por ende, estaba repleto de otros sentidos muy distintos-, sino que, además, significó aunque sea por un momento la suspensión del orden, no queriendo decir con ello más que la suspensión de un estado de las cosas que permite vislumbrar la posibilidad de que algo se transforme (siendo la dirección del cambio aún indeterminada). No se trató de una refundación, pero sí de la condición de posibilidad para que ello sucediera: la revelación y puesta en escena de la contingencia.

Así, afirmar que las jornadas decembrinas fueron un "momento político" de suspensión del orden no implica sostener a la vez el carácter politizado, transformador, progresista o de izquierda de los múltiples sentidos que se expresaban en única consigna. Es así que Rinesi reconoce dos grandes corrientes presentes en el "que se vayan todos": por un lado, entonces, el que provenía de una fuerte politicidad previa de los sectores más afectados por la reforma operada durante la década que se cerraba, que hacía tiempo que venían expresando su disconformidad y sus reclamos; del otro, el que provenía de aquella pulsión "anti-política" (...), y que expresaba (por mucho que alguna de sus consignas haya sido recogida y levantada como bandera, después, por este o aquel grupo más o menos libertario) el sentido común de la derecha televisiva más previsible y más convencional (Rinesi, 2010: 41).

"Que se vayan todos" era, entonces, una frase que operaba como un nombre, en el sentido de que podía articular lo heterogéneo, aunque tiempo después esas "demandas diferenciales" que componían la cadena se presentaran como irreconciliables entre sí. Es decir, si bien es cierto que toda cadena equivalencial es por definición inestable, precaria, contingente, parcial y temporal, podríamos decir que en este caso el nombre nunca fue lo suficientemente productivo como para que "lo común" se impusiera sobre los elementos diferenciales.

Tal vez había algo en ese nombre que, antes que contribuir a instituir una nueva identidad política, obstaculizaba la conformación de un nosotros. En este sentido, el sesgo negativo de la consigna "que se vayan todos" puede asociarse al discurso anti-político, puesto que éste expresa el rechazo al conflicto, a la legitimidad y la conveniencia del conflicto, a través del cual se constituye la comunidad política. Entonces, si el problema es que "son todos iguales", "que se vayan todos" puede ser un primer paso, tal vez hasta necesario, pero no resulta suficiente para producir la diferencia política a partir de la cual se puede restituir el vínculo representativo. Se necesita de un "otro" y, más precisamente, de una disputa por definir y nombrar a ese "otro", pero es el propio discurso anti-político el que impugna dicho debate.

A modo de conclusión, sintetizamos nuestra interpretación de la crisis de representación política argentina durante los '90 (una década que se extiende hasta el 2002) refiriendo a un paisaje político que podemos describir como el desierto mudo de la indistinción, para dar cuenta con ello de que lo que faltaba era la palabra y el conflicto. $Y$ por esto mismo es que no resulta llamativo, por más sorpresivas y novedosas que hayan sido las cacerolas y las plazas llenas, que una situación tal, que podría ser calificada de estancamiento político, haya encontrado una salida a través del conflicto. Aun como reacción antes que como acción, aun con sus rasgos antipolíticos, las jornadas decembrinas 
pusieron en escena la necesidad de una ciudadanía movilizada y presente para constituir aquello que denominamos representatividad, que no es otra cosa que la comunidad, el pueblo que falta. Compréndase bien, no estamos diciendo con ello que aquel 19 y 20 fue la rememoración de otros tiempos ya lejanos, a la manera de una visión idealizada y nostálgica de un pasado que fue mejor. Por el contrario, se trata de una interpretación que intenta dar cuenta de que la palabra y el conflicto son los componentes claves del trabajo de la política: construir un pueblo ${ }^{15}$ que siempre va a faltar, porque es un trabajo imposible y necesario. Teniendo esto en cuenta, si la crisis de representación es el quiebre de la creencia, habría que preguntarse, una vez más, en qué se dejó de creer. Nuestra respuesta es que se dejó de creer en la palabra y en el conflicto, lo que es lo mismo que decir que se dejó de creer que era necesaria la tarea de construir un pueblo, una comunidad de sentido. $\mathrm{Y}$ si los partidos políticos fueron los principales afectados por esta crisis es porque "olvidaron" que una de sus más importantes funciones es la de contribuir a establecer la diferencia propiamente política a partir de la cual se conforma la comunidad política de la que forman parte.

\section{Diez años después}

Si bien en términos generales cualquier trabajo de interpretación sobre el pasado -y más aún sobre el pasado reciente- forma parte de la disputa política por el sentido del presente, esta afirmación se torna especialmente pertinente si queremos comprender el proceso que comenzó en Argentina en 2003 con la presidencia de Néstor Kirchner. Es decir, si se trata de responder cómo operó la salida de una de las crisis políticas más importantes que ha atravesado la Argentina, resulta fundamental analizar las características de esa crisis, el sentido que le atribuimos y el proceso de largo plazo que desembocó en ella.

Así, para comprender qué sucedió con las relaciones de representación desde 2003 hasta hoy resulta particularmente necesario dar cuenta de la crisis de 2001, porque ese acontecimiento es la marca de nacimiento del kirchnerismo, entendiendo que Néstor Kirchner refunda la relación de representación, en parte, marcando una ruptura con esa década como pasado demonizado, sedimentando una significación retroactiva de los acontecimientos de 20012002 (Aboy Carlés, 2005). Estas características propias del kirchnerismo hacen que resulte imprescindible comprender qué estamos diciendo cuando hablamos de la crisis de representación política durante los '90.

Teniendo esto en cuenta, se podría alegar que Kirchner comprendió muy bien la importancia que tenía la disputa por el sentido del pasado reciente. Pues si recordamos la multiplicidad de sentidos presentes ese 19 y 20 de diciembre,

\footnotetext{
${ }^{15}$ Según expone Laclau en La razón populista (2005), la construcción del pueblo no sólo es el trabajo de la política par excellence, sino también, y por esta misma razón, un caso paradigmático de la teoría de la representación, porque "revela a la representación por lo que es: el terreno primario de constitución de la objetividad de lo social" (Laclau, 2005: 206). Construir al pueblo requiere, entonces, de una doble operación retórica: por un lado, la dimensión catacrética, y por otro, la dimensión que se expresa en la figura de la sinécdoque. Y ello porque ya no se trata, solamente, de que un significante se vacíe para asumir la representación del pueblo (y que en ese movimiento el representante agregue algo a la identidad de los representados), sino también de que esa particularidad se asuma como la "parte" que viene a representar al todo, la plebs que quiere ser populus.
} 
vemos que de esta disputa dependía, en parte, si después del 2001 se conformaba un escenario propicio para la rearticulación de una nueva hegemonía del discurso neoliberal, o no. Ariel Wilkis y Gabriel Vommaro lo expresan de la siguiente forma:

Mientras el pasado de estabilidad y auge fuera visto como la bonanza que debía volver, el discurso del orden neoliberal seguiría teniendo un terreno fértil donde construir una nueva articulación hegemónica. La disputa por procesar el pasado reciente, entonces, era parte de las urgencias del futuro. Si el discurso de la expoliación se volvía contra la confiscación de los ahorros de manera patrimonialista, su familiaridad con el discurso neoliberal de la reducción de la política entendida como un "costo", podía ser mantenido sin contradicción (Wilkis y Vommaro, 2002: 114).

Por otra parte, dado que un trabajo de interpretación pone en juego el valor heurístico, la productividad explicativa de las categorías que sostienen el análisis, esperamos haber mostrado que ciertas nociones que las ciencias sociales utilizan asiduamente -el ideal de política transparente, sin opacidad, y la representación como reflejo, ambas negadoras del poder instituyente de lo político- resultan limitantes a la hora de dar cuenta de los sentidos de una crisis política como la de 2001.

Esa limitación se confirma, además, cuando vemos que sostener estos mismos supuestos para analizar al kirchnerismo implicaría, o bien pensar que el gobierno que asumió en 2003 tuvo éxito en su estrategia representativa porque logró "reflejar" los "verdaderos" intereses sociales, o bien recurrir a una explicación que combine la situación de excepción con teorías aggiornadas de la manipulación política, que en los últimos tiempos incluyen lo que podríamos denominar las "teorías de la simulación". ${ }^{16}$ En cambio, creemos que centrar el análisis en los mecanismos de construcción de una identidad política permite explicar cómo se reconstruyó la representatividad del lazo de representación, cómo dicho lazo se resquebrajó con una parte de la sociedad a partir del conflicto que mantuvo el gobierno de Cristina Fernández con el sector agropecuario en $2008^{17}$, y cómo pudo ser reconstituido al punto de ganar en las últimas elecciones presidenciales con el $54 \%$ de los votos, y con una diferencia de más de más de 40 puntos sobre el segundo.

Ahora bien, ese conflicto no implicó una nueva crisis de representación, y podríamos decir que eso se debió, en parte, a que las condiciones de

\footnotetext{
${ }^{16}$ Cuando decimos teorías aggiornadas de la manipulación nos referimos a aquellas que hacen de la población sumida en la crisis un sujeto más manipulable, menos autónomo, con menos herramientas para juzgar y evaluar la gestión y las políticas llevadas a cabo por el gobierno. Las "teorías de la simulación" son una versión vulgar de aquellas, y serían las que sostienen que la principal herramienta para manipular y engañar a la población sería la simulación, especialmente de la presidenta Cristina Fernández, sobre todo desde la muerte de Néstor Kirchner. Al asumir este tipo de explicaciones no es posible preguntarse por la reconstrucción de la representatividad (término que supone que tanto representados como representantes son sujetos políticamente activos en la conformación de una identidad), ya que la aceptación, la legitimidad del nuevo gobierno se explicaría, solamente, por la situación de excepción (en el caso del gobierno de Néstor Kirchner), y no ya por cierto éxito en la reconstrucción del lazo político a través de la constitución del sentido del pasado y del futuro, pero también de la política, del Estado, de la vida colectiva, etc.

${ }^{17}$ Para un análisis de las relaciones de representación durante el conflicto que desató la resolución 125, ver Yabkowski (2010).
} 
posibilidad para que ello sucediera no estaban dadas. Es decir, no faltaban ni las palabras ni los clivajes, sino todo lo contrario. Si recordamos esta situación es para contraponerla a ese desierto mudo de la indistinción que a nuestro entender caracterizó los años 90. Pero sobre todo nos sirve para seguir sosteniendo que el conflicto político es un elemento esencial en la representación, en la construcción de una identidad política, y que es por ello que su existencia se torna imprescindible, incluso en los momentos de "normalidad". Lo que queremos decir con esto es que las palabras y los conflictos políticos no deben implicar siempre y necesariamente un momento de refundación, sino que son también parte de "la política". De esta manera, pueden contribuir a mantener, extender e intensificar una identidad política, y a reforzar el carácter ordenador de un clivaje ya instituido, así como también pueden provocar que la extensión de la "cadena de equivalencias" se reduzca y que las fronteras que dan forma al espacio de representación se reacomoden. Es decir, las palabras, los conflictos y los clivajes pueden explicar, por ejemplo, un cambio de gobierno o el alto grado de representatividad de un gobernante, mientras que la ausencia de ellos puede explicar una crisis de representación. En este sentido, afirmamos que esos tres elementos contribuyen más a la estabilidad política de lo que suele pensarse.

\section{Bibliografía}

ABAL MEDINA, Juan (h) (2004), La muerte y la resurrección de la representación política, Fondo de Cultura Económica, Buenos Aires.

ABAL MEDINA, Juan (h.) y Julieta SUÁREZ CAO (2002), "La competencia partidaria en la Argentina: sus implicancias sobre el régimen democrático". En CAVAROZZI Marcelo y Juan Manuel ABAL MEDINA, (comp.), El asedio a la política. Los partidos latinoamericanos en la era neoliberal, Homo SapiensKonrad Adenauer Stiftung, Rosario.

ABOY CARLÉS, Gerardo (2005), "Populismo y democracia en la Argentina contemporánea. Entre el hegemonismo y la refundación", en Estudios Sociales, año XV, primer semestre, $n^{\circ} 28$, pp. 125-137.

ALEM, Beatriz (2007), "El Frepaso, problemas de una identidad lábil", en RINESI Eduardo, Gabriel NARDACCHIONE y Gabriel VOMMARO, (eds.), Los lentes de Víctor Hugo. Transformaciones políticas y desafíos teóricos en la Argentina reciente, UNGS-Prometeo, Buenos Aires.

AUSTIN, John (2003), Cómo hacer cosas con palabras, Paidós, Buenos Aires.

BASSET, Yann (2003), "Abstención y voto negativo. De la interpretación sociológica a la lógica política", en CHERESKY Isidoro y J. M. BLANQUER, (comps.), De la ilusión reformista al descontento ciudadano. Las elecciones en Argentina, 1999-2001, Homo Sapiens, Rosario. 
CALVO, Ernesto y Marcelo ESCOLAR (2005), La nueva política de partidos en la Argentina. Crisis política, realineamientos partidarios y reforma electoral, Buenos Aires, Prometeo.

CHERESKY, Isidoro (1999), La innovación política, Eudeba, Buenos Aires.

(2001), "Hipótesis sobre la ciudadanía argentina contemporánea", en CHERESKY Isidoro e Inés POUSADELA (comps.), Política e instituciones en las nuevas democracias latinoamericanas, Paidós, Buenos Aires.

(2006), "La ciudadanía y la democracia inmediata", en CHERESKY Isidoro (comp.), Ciudadanía, sociedad civil y participación política, Miño Dávila, Buenos Aires.

KATZ, Richard y Peter MAIR (1995), "Changing models of party organization and party democracy. The emergence of the cartel party", en Party Politics, Vol. 1, No 1, pp. 5-28..

LACLAU, Ernesto (2005), La razón populista, Buenos Aires, Fondo de Cultura Económica.

------- (2000), Nuevas reflexiones sobre la revolución de nuestro tiempo, Nueva Visión, Buenos Aires.

LACLAU, Ernesto y Chantal MOUFFE (2004), Hegemonía y estrategia socialista. Hacia una radicalización de la democracia, Fondo de Cultura Económica, Buenos Aires.

MANIN, Bernard (1992), "Metamorfosis de la representación", en DOS SANTOS Mario (coord.), ¿Qué queda de la representación política?, CLACSO/Nueva Sociedad, Caracas.

MARCHART, Oliver (2009), El pensamiento político posfundacional. La diferencia política en Lefort, Nancy, Laclau y Badiou, Fondo de Cultura Económica, Buenos Aires.

MOCCA, Edgardo (2002), "Defensa de la política (en tiempos de crisis)", en NOVARO Marcos (comp.), El derrumbe político en el ocaso de la convertibilidad, Norma, Buenos Aires.

MUSTAPIC, Ana María (2002), "Argentina: la crisis de representación y los partidos políticos", en América Latina Hoy, diciembre, año/vol. 32, pp. 163-183.

NANCY, Jean-Luc (2000), La comunidad inoperante, LOM, Santiago de Chile.

NOVARO, Marcos (1994), Pilotos de tormentas. Crisis de representación y personalización de la política en Argentina (1989-1993), Letra Buena, Buenos Aires.

------- (2000), Representación y liderazgo en las democracias contemporáneas, Homo Sapiens, Rosario.

NOVARO, Marcos y PALERMO, Vicente (1998): Los caminos de la centroizquierda. Dilemas y desafíos del Frepaso y de la Alianza, Losada, Buenos Aires.

PANEBIANCO, Angelo (1995), Modelos de partido. Organización y poder en los partidos políticos, Alianza, Madrid. 
POUSADELA, Inés (2003), "La oposición progresista frente al consenso neoliberal. Ensayo acerca de la relación entre política y economía en la Argentina de los años '90', en CHERESKY Isidoro y J-M. BLANQUER, (comps.), De la ilusión reformista al descontento ciudadano. Las elecciones en Argentina, 1999-2001, Homo Sapiens, Rosario.

- (2004), "Los partidos políticos han muerto. ¡Larga vida a los partidos!", en CHERESKY Isidoro y J-M. BLANQUER, (comps.), ¿Qué cambió en la política argentina? Elecciones, instituciones y ciudadanía en perspectiva comparada, Homo Sapiens, Rosario.

(2007), "Entre la deliberación política y la terapia de grupo. La experiencia de las asambleas barriales-populares". Informe final del concurso: Partidos, movimientos y alternativas políticas en América Latina y el Caribe. Programa Regional de Becas CLACSO. Disponible en: $<$ http://bibliotecavirtual.clacso.org.ar/ar/libros/becas/semi/2004/partidos/pousa.p df $>$ Acceso 27 de noviembre de 2008.

RANCIÈRE, Jacques (1996), El desacuerdo. Política y filosofía, Buenos Aires, Nueva Visión.

RINESI, Eduardo (2007), "Representatividad, legitimidad, hegemonía. Los dilemas de la representación política después del desbarajuste", en EMILIOZZI Sergio, Mario PECHENY y Martín UNZUÉ, (comps.), La dinámica de la democracia. Representación, instituciones y ciudadanía en Argentina, Prometeo, Buenos Aires.

(2010), "Política y corporaciones", en ARONSKIND Ricardo y Gabriel VOMMARO, (comps.), Campos de batalla: las rutas, los medios y las plazas en el nuevo conflicto agrario, Prometeo-UNGS, Buenos Aires.

SARTORI, Giovanni (1992), Partidos y sistemas de partidos, Alianza, Madrid.

TORRE, Juan Carlos (2003), "Los huérfanos de la política de partidos. Sobre los alcances y la naturaleza de la crisis de representación partidaria", en Desarrollo Económico, enero-marzo, Vol. 42, pp. 647-665.

VOMMARO, Gabriel (2003), '“Lo que quiere la gente'. Los sondeos de opinión pública como herramienta política. El caso de las elecciones nacionales de 1999", en CHERESKY Isidoro y J-M. BLANQUER, (comps.), De la ilusión reformista al descontento ciudadano. Las elecciones en Argentina, 1999-2001, Homo Sapiens, Rosario.

YABKOWSKI, Nuria (2010), El desierto mudo de la indistinción. La crisis de representación política argentina, (1990-2002) en debate. Tesis de Maestría de la Universidad de Buenos Aires en Investigación en Ciencias Sociales. Director Dr. Eduardo Rinesi. Fecha de defensa: 28 de mayo de 2010.

------ (2010), "Nosotros, ellos...Todos. Los sentidos de la representación política y los recursos discursivos utilizados para ganar legitimidad en el conflicto", en ARONSKIND Ricardo y Gabriel VOMMARO, (comps.), Campos de batalla: las rutas, los medios y las plazas en el nuevo conflicto agrario, Prometeo-UNGS, Buenos Aires. 


\section{Cuadro 1}

Elecciones legislativas 2001

\begin{tabular}{|l|c|c|c|c|}
\hline \multicolumn{1}{|c|}{ Partidos } & $\begin{array}{c}\text { Votos } \\
\text { obtenidos }\end{array}$ & $\begin{array}{c}\text { \% sobre } \\
\text { total } \\
\text { votos } \\
\text { positivos }\end{array}$ & $\begin{array}{c}\text { \% sobre } \\
\text { total } \\
\text { votos } \\
\text { válidos }\end{array}$ & $\begin{array}{c}\% \text { sobre } \\
\text { total } \\
\text { padrón }\end{array}$ \\
\hline PJ & 4.809 .495 & $34,0 \%$ & $26,6 \%$ & $19,3 \%$ \\
\hline Alianza & 3.058 .569 & $21,6 \%$ & $16,9 \%$ & $12,3 \%$ \\
\hline APR & 174.068 & $1,2 \%$ & $1,0 \%$ & $0,7 \%$ \\
\hline Provinciales & 1.200 .118 & $8,5 \%$ & $6,6 \%$ & $4,8 \%$ \\
\hline Izquierda & 1.499 .293 & $10,6 \%$ & $8,3 \%$ & $6,0 \%$ \\
\hline Centro-izquierda & 1.772 .438 & $12,5 \%$ & $9,8 \%$ & $7,1 \%$ \\
\hline Otros & 1.626 .215 & $11,5 \%$ & $9,0 \%$ & $6,5 \%$ \\
\hline $\begin{array}{l}\text { Total votos } \\
\text { positivos }\end{array}$ & $\mathbf{1 4 . 1 4 0 . 1 9 6}$ & $\mathbf{1 0 0 \%}$ & $78,2 \%{ }^{*}$ & $56,83 \% *$ \\
\hline Votos en blanco & 1.704 .514 & --- & $9,4 \%$ & $6,8 \%$ \\
\hline Votos nulos & 2.261 .332 & --- & $12,5 \%$ & $9,1 \%$ \\
\hline $\begin{array}{l}\text { Total votos } \\
\text { válidos }\end{array}$ & $\mathbf{1 8 . 1 0 6 . 0 4 2}$ & --- & $\mathbf{1 0 0 \%}$ & --- \\
\hline Ausentes & 6.777 .624 & --- & --- & $27,2 \%$ \\
\hline Total electores & $\mathbf{2 4 . 8 8 3 . 6 6 6}$ & --- & --- & $\mathbf{1 0 0 \%}$ \\
\hline
\end{tabular}

Fuente: Calvo y Escolar (2005).

*Estos datos no aparecen calculados en el cuadro de Calvo y Escolar. 